I am therefore not without a certain confidence that, as was the case with myself, his view of the relative advantages of the two operations will be modified by an increased experience of both. I am, Sirs, yours faithfully,

Leeds, April 8th, 1906.

B. G. A. Mornihan.

\section{METHYLATED CHLOROFORM.}

\author{
To the Editors of THE LANCET.
}

SIRS,-I noted your answer to a correspondent in THE LANCET of March 31st regarding methylated chloroform. As this was brought under my notice in a very practical way about a year ago, perhaps I may be permitted to make a few brief remarks in support of some of your statements. At a certain hospital where I was resident medical officer it was decided after careful investigation to try methylated chloroform instead of ethylated chloroform as the former is just about half the price of the latter and the hospital finances were such that the utmost economy had to be exercised. Experience quite justified the change. As resident medical officer the duty of giving the anæsthetic fell to me and I was also able to note the after-effects.

My experience coincides with that of those who maintain that methylated chloroform is quite as good as ethylated chloroform. I experienced no greater difficulty in the administration of the anæsthetic and $I$ found that the patients went under as well and as easily after exbibiting the same phenomena as when ethylated chloroform was given. I did not find after-effects more marked or more severe. In the majority of cases, especially if they had been in hospital for a day or two and thus had been well prepared, there were no after-effects. In a few cases there were headache, sickness, and vomiting, but these did not occur in a larger percentage of cases than one meets with when ethylated chloroform is given. I had eight months' experience in the administration of methylated chloroform, having during the preceding four months given ethylated chloroform, and I did not encounter any effect at the time of administration or afterwards which would justify one in saying that the former is more dangerous and more disagreeable than the latter. The fact that the methylated form is used in many large hospitals by men who are specialists in anæsthetic work shows that its value is well recognised.

I am, Sirs, yours faithfully,

March 31st, 1906 J. Allan, M.B.

\section{SHERRY AND OTHER FORMS OF ALCOHOL} IN ILLNESSES CHRONIC AND ACUTE.

\section{To the Editors of THE LANCET.}

SIRS, - When I first came to Spain some seven years ago I bad as full a horror of sherry as any other equally ignorant Englishman. One of the first things I noticed on meet ing in consultation my Spanish brothers was the universality with which they all ordered sherry instead of brandy. This is the more striking because they make very good brandy in Soain and French brandy is quite as accessible here as in England. I find that sherry is generally very much better borne by the very ill patient than brandy (a light sherry called "Fino"); one misses the flushing of the face, the hardness of the pulse, which brandy produces in doses of one to three ounces in 24 hours, yet in that time one will have been able to give from six to eight ounces of a light sherry, containing an equal amount of the higher ethers with quite enough stimulant for one's purpose and far more digestible. In convalescence or in more chronic troubles I prefer a heavy sherry, an "Oloroso" or an "Amontillado," and this latter always after meals. The light sherry has this great advantage over brandy-one that must appeal to every gourmet-that on an empty stomach it is more palatable. Who would choose to drink brandy on the stomach condition which exists in any illness?

The indications most commonly accepted for giving alcohol in acute illnesses are debility, heart failure, anorexia, high fever, \&c. Pneumonia, delirium tremens, and typhoid fever are types of acute diseases in which one might desire to exhibit alcohol.

I have treated pneumonia now for two years with sherry when I wanted to give alcohol. As soon as I see that fever is beginning to overtax the strength, generally about the third or fourth day, I give one glass (sherry) of sherry every four hours. I also regard a falling-off in taking of food, of which I prefer milk, whey, or Mellin's food made with milk, as an indication to begin alcohol; in this case I order half a glass every four hours, or the same amount in food. The sherry I use in such cases is a light sherry-e.g., Nectar of Gonzalez, or a Manzanilla such as Divina Pastora for poorer patients. I increase this if there is any sign of beart failure or increasing debility up to a wineglassful every hour, or in one or two teaspoonful doses every ten minutes if necessary. The effects of such wines (and I only refer to them as types) is to steady the pulse, to clear the head, to clean the mouth, and perhaps for this reason to help the appetite, and sometimes to open the bowels; they also act as a diuretic. The patient, whether English, French, or Spanish, nearly always prefers sherry to brandy if he be allowed to try both. When the crisis is passed and the lower level established I give a heavier wine, such as Trafalgar, a glass every three or four hours, and I keep this up in diminishing quantities-i.e., four hourly, six hourly, three times a day, and twice a day after eating-until the patient is well. The only medicines I have used for three years in the treatment of pneumonia have been a little Dover's powder for the hard, painful cough, and later a little ammonium carbonate when the cough is already free, the latter nearly always as a placebo. The last case which I treated on champagne, digitalis, \&c. certainly came through a very serious illness but remained with a hard dry cough which I could only get rid of by depriving him of all wines. He had a glass of champagne every two hours and for a short period (about 12 hours) every hour; all the time he was taking this he was very flushed and had much headache but his pulse had sunk to 40 and his nose and lips were blue. Parenthetically I may remark that acetic acid in wines gives rise to stomachic cough; a man with a hard, dry, useless cough who is drinking a cheap claret will frequently lose it if given an old Burgundy instead. I have occasionally as a last resource gone back to brandy. In one case the patient when I first saw her had a temperature of $41^{\circ} \mathrm{C}$. (or $106^{\circ} \mathrm{F}$.) and a pulse of 130, and in despair I advised her medical attendant to try brandy. One would scarcely expect betterment in such a case but she appeared more uncomfortable and the delirium was more marked after the change of alcohol.

In those cases of delirium tremens in which it is desirable not to do away with alcohol all at once I have found sherry very useful. A mixture containing digitalis, bromides, or chloral, with a dessertspoonful of a heavy sherry sweetened by a little glycerine prevents, firstly, the collapse and, secondly, helps to alleviate the troublesome craving, while as regards fever, appetite, \&c., it acts as in pneumonia. In typhoid fever I have had too little direct experience to be able to say much, most of the cases I have seen being in consultation, but I find the same idea is followed. The Spanish medical man, however, rarely uses the heavier wines, nearly always keeping throughout to the lighter kinds. In chronic troubles-e.g., that languidness which one finds in the business man, anorexia, headache, and anæmia (though in this $I$ think a Burgundy better) $-I$ have found a light sherry most useful, one glass at lunch and one at dinner. If the luncheon glass causes heaviness, which it will in people unaccustomed to alcohol, then two glasses may be taken at dinner time, one with the soup and one with the fish. Far from producing biliousness the patient finds himself quite clear and with a delightful feeling of peace towards all men the next morning; and the greatest test of the goodness of any wine is, when drunk with discretion, the feeling better for it the next morning. I have often found the opposite with port, even with discretion, the patient being fractious the next day.

I have gone so far as to give sherry in cases of dyspepsia in which I susvected defective secretion and motility and I have met with some, though not unvaried, success: the modern love for whisky has either destroyed the palate or has led to an inordinate love of cheapness. The stomach, however, gains in tone and the mouth becomes cleaner tasting, and the bowels are frequently opened without other aid. For children sherry is undonbtedly the best alcohol; it can be sweetened and it does not so easily intoxicate as brandy, teaspoonful and half-teaspoonful doses, hourly or half-hourly, can be stood; from 15 to 30 minims hourly or two-hourly is a useful dose. In Jerez, where sherry is drunk in large quantities, and, in fact, all throughout the sonth of Spain, cirrhosis and gout are practically unknown.

Believing these things to be so I think that we ought as a profession, f others confirm my experience, to help to 